\title{
Multicenter Study on Clinical Evaluation of Disposable Syringes Pre-loaded with Growth Hormone (Genotropin KabiQuick)
}

Seizo Suwa, Katsuhiko Tachibana, Yoshihide Ohyama, Masatoshi Fujimoto, Osamu Shinohara and Etsuro Tokuhiro

Department of Pediatrics, Kanagawa Children's Medical Center (S.S., K.T.),

Kitasato University (Y.O.), St. Marianna University (M.F.), Tokai University (O.S.),

Odawara City Hospital and Yokohama City University (E.T.), Kanagawa, Japan

\begin{abstract}
A short term multicenter study on evaluation of the usefulness, acceptability and tolerability of Genotropin KabiQuick (GKQ) was carried out in 36 patients with classical growth hormone $(\mathrm{GH})$ deficiency. Of 36 patients or their parents, $32(88.9 \%)$ evaluated $\mathrm{GKQ}$ as superior in preparative procedure to the conventional injection syringe system. Thirty $(83.3 \%)$ including all of the 6 self-injection patients evaluated that dosing with GKQ was easier. Thirty-two (88.9\%) said that GKQ could be handled in a more sanitary condition. Twenty-six $(72.2 \%)$ felt that the handling of GKQ was easier. The average time needed for each injection with GKQ was $4.0 \pm 3$. $2 \mathrm{~min}$. which was significantly shorter than that with the conventional system $(7.8 \pm 6.2 \mathrm{~min})$. Ten, twelve and thirteen patients complained that GKQ gave more, equal and less pain respectively. Nineteen (52.8\%) commented that the plunger of GKQ was hard to push. Twenty-two (61.1\%) preferred GKQ and 5 (13.9\%) reverted to the conventional system for future treatment. Doctors concerned with this study assessed that GKQ was useful in 27 patients (75\%), but not useful in 2 patients (5.6\%). It is concluded that GKQ is an easy handling device which provides quick, safe and sterile daily injections for patients or parents, but an easily movable plunger, a smaller size device and a lower dose-system GKQ are requested for further improvement.
\end{abstract}

Key words: Genotropin KabiQuick, all-in-one injection system, growth hormone, growth hormone deficiency, KabiPen

Correspondence: Dr. Seizo Suwa, Kanagawa Children's Medical Center, Hospital for Sick Children, 138-4 Mutsukawa 2-chome, Minami-ku, Yokohama 232 Japan.

This study was supported in part by grants from the Ministry of Health and Welfare, Japan and by a research grant from the Foundation for Growth Science in Japan.

\section{Introduction}

The utilization of human growth hormone $(\mathrm{GH})$ is rapidly increasing in the treatment not only of GH deficient children (GHD) but also of other short children such as those with Turner's syndrome, because of its wider availability. Daily subcutaneous injections 
of $\mathrm{GH}$ are reportedly more effective than the same weekly dose given intramuscularly divided into two or three doses [1-4]. Recently it has been common practice for $\mathrm{GH}$ to be self-injected at home. Therefore, there is a strong need to simplify the methods of administration. However, the conventional procedure of $\mathrm{GH}$ injection using a needled syringe and vial is considered inconvenient for patients and parents, because the procedure needs the reconstitution of vialed $\mathrm{GH}$ powder with ampuled diluent, and the re-transfer of an adequate dose of $\mathrm{GH}$ solution into the syringe for each injection. Therefore several devices for injection such as pocket injection pens $[5,6]$ have been developed to provide an easier injection system for patients to cope with daily injections at home. But these injectors still require several troublesome procedures or specific $\mathrm{GH}$ vials containing preservatives. Recently a more convenient all-in-one single use injection system, Genotropin KabiQuick (GKQ), has been developed [7]. This system consists of a single use disposable injection syringe and special holder which encloses a two-compartment cartridge (one compartment for $\mathrm{GH}$ powder and the other for dilution water) as a mixing device for reconstitution. GKQ holds pre-prepared $\mathrm{GH}$ in a cartridge (2, 3 or $4 \mathrm{IU})$ for a single injection, hence $\mathrm{GH}$ solution contains no preservative.

The aim of this study was to evaluate the usefulness, acceptability and tolerability of the new injection system in patients with GHD.

\section{Subjects and Methods}

\section{The patients}

Thirty-six patients with classical GHD (5 from Yokohama City University Hospital, 3 from Odawara City Hospital, 7 from Kitasato University Hospital, 5 from St. Marianna University Hospital, 5 from Tokai University Hospital and 11 from Kanagawa Children's Medical Center) were enrolled in this study. Twenty-nine of them were idiopathic in nature ( 27 boys, 2 girls) and 7 organic ( 4 boys, 3 girls).

The patients ranged in age from 6.1 years to 19.3 years (mean 12.6 years), and had been treated with $\mathrm{GH}$ for 3.5 years in average (range from 2 months to 12.5 years). The weight of the patients ranged from $15.3 \mathrm{~kg}$ (9.3 years, boy) to $55.0 \mathrm{~kg}$ ( 16.9 years, boy) and averaged $35.0 \pm 11.0 \mathrm{~kg}$. The height ranged from $106.4 \mathrm{~cm}$ (6.1 years, boy) to $157.4 \mathrm{~cm}$ (16.0 years, boy) and averaged $136.3 \pm 15.8 \mathrm{~cm}$. At the time prior to the study, the patients received recombinant $\mathrm{GH}(4$ or 12 IU Genotropin per vial) of $0.45 \pm 0.07 \mathrm{IU} / \mathrm{kg} /$ week in average, generally injected subcutaneously

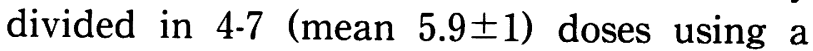
conventional disposable needled insulin syringe.

\section{The injection syringe}

The all-in-one disposable syringe, Genotropin KabiQuick (GKQ) was used. Of the three kinds of dose-system of $\mathrm{GKQ}$ preloaded with a cartridge containing 2, 3 or 4 IU of recombinant $\mathrm{GH}$ powder in one compartment and $0.5,0.75$ or $1 \mathrm{ml}$ water for reconstitution in another compartment respectively, a single dose-system was selectively or two kinds of dose-system were alternatively used for one patient. Selection of the dose-system of GKQ depended upon the patient's body weight and number of injection times per week.

\section{The person responsible for injection}

Six patients performed self-injection, 28 were injected by a parent during the study. Two patients were alternatively injected by themselves or a parent.

\section{The study protocol}

The conventional syringe system was replaced with the GKQ system, and GH treatment was continued without any change of dose and injection times per week. The trial 


\section{Evaluation of Genotropin KabiQuick}

Table 1. Patient's evaluation of preparative procedure with Genotropin KabiQuick compared with the conventional injection system

\begin{tabular}{lccc}
\hline $\begin{array}{l}\text { person responsible } \\
\text { for injection }\end{array}$ & $\begin{array}{c}\text { more } \\
\text { convenient }\end{array}$ & equal & $\begin{array}{c}\text { less } \\
\text { convenient }\end{array}$ \\
\hline patient & 4 & 2 & 0 \\
pt. and parent & 2 & 0 & 0 \\
parent & 26 & 2 & 0 \\
\hline total & 32 & 4 & 0 \\
& $(88.9 \%)$ & $(11.1 \%)$ & \\
\hline
\end{tabular}

Table 2. Patient's evaluation of facility in handling of Genotropin KabiQuick compared with the conventional injection system

\begin{tabular}{lccc}
\hline $\begin{array}{l}\text { person responsible } \\
\text { for injection }\end{array}$ & easier & equal & $\begin{array}{c}\text { more } \\
\text { difficult }\end{array}$ \\
\hline patient & 3 & 3 & 0 \\
pt. and parent & 2 & 0 & 0 \\
parent & 21 & 6 & 1 \\
\hline \multicolumn{1}{c}{ total } & 26 & 9 & 1 \\
& $(72.2 \%)$ & $(25.0 \%)$ & $(2.8 \%)$ \\
\hline
\end{tabular}

was conducted as an open study between December 1991 and January 1992. The study period in each patient was between 1 and 4 weeks. Before the start of the study, demonstrations and instructions in the function and using technique of the GKQ were given to each patient and/or parent by a doctor, and the patient and parent practised using the injector at a regular visit to the out-patient clinic. Informed consent was obtained from all patients and/or parents before the study. For evaluating the new injection system, a questionnaire with 9 items was completed at the end of the study either by the patient and/ or the parent, depending on the age of the patient and the type of question posed.

\section{Results}

Of 36 patients or parents, $32(88.9 \%)$ evaluated that the preparative procedure with Genotropin KabiQuick (GKQ) such as reconstitution of $\mathrm{GH}$, needle attachment and expiration of air from the syringe was more convenient than that with the conventional syringe injection system (Table 1). Four patients or
Table 3. Patient's impression on sanitary condition in handling of Genotropin KabiQuick compared with the conventional injection system

\begin{tabular}{lccc}
\hline $\begin{array}{l}\text { person responsible } \\
\text { for injection }\end{array}$ & $\begin{array}{c}\text { more } \\
\text { sanitary }\end{array}$ & equal & $\begin{array}{c}\text { less } \\
\text { sanitary }\end{array}$ \\
\hline patient & 5 & 1 & 0 \\
pt. and parent & 2 & 0 & 0 \\
parent & 25 & 3 & 0 \\
\hline \multicolumn{1}{c}{ total } & 32 & 4 & 0 \\
& $(88.9 \%)$ & $(11.1 \%)$ & \\
\hline
\end{tabular}

Table 4. Patient's evalution of facility in dosing with Genotropin KabiQuick compared with the conventional injection system

\begin{tabular}{lccc}
\hline $\begin{array}{l}\text { person responsible } \\
\text { for injection }\end{array}$ & easier & equal & $\begin{array}{c}\text { more } \\
\text { difficult }\end{array}$ \\
\hline patient & 6 & 0 & 0 \\
pt. and parent & 1 & 1 & 0 \\
parent & 23 & 5 & 0 \\
\hline \multicolumn{1}{c}{ total } & 30 & 6 & 0 \\
& $(83.3 \%)$ & $(16.7 \%)$ & \\
\hline
\end{tabular}

Table 5. Time consumed for each injection

\begin{tabular}{lcc}
\hline & & Minutes(M \pm SD) \\
\hline Genotropin KabiQuick & (N 34) & $4.0 \pm 3.2$ \\
conventional injection & (N 34) & $7.8 \pm 6.2$ \\
\hline
\end{tabular}

parents found the two systems equally convenient, and none expressed GKQ was less convenient. Twenty-six (72.2\%) felt that the handling of GKQ was easier than the conventional system, but 9 felt it equal to it and only one more difficult (Table 2). Thirty-two (88.9\%) had an impression that the sanitary condition in handling GKQ was superior to the conventional system (Table 3 ). Thirty (83.3\%) of 36 patients or parents including all of the 6 self-administration patients answered that dosing with GKQ was easier than with the conventional system but 6 thought there was no difference between the two systems (Table 4). The average times consumed for each injection including preparative procedure are shown in Table 5 . The time needed for the GKQ system was significantly shorter $(p<$ $0.05)$ than that for the conventional system.

Ten (27.8\%), 12 (33.3\%) and 13 (36.1\%) patients complained that injection by GKQ gave more pain, equal pain and less pain than 
Table 6. Patient's complaint of injection pain by Genotropin KabiQuick compared with the conventional injection system

\begin{tabular}{lccc}
\hline \multirow{2}{*}{$\begin{array}{l}\text { person responsible } \\
\text { for injection }\end{array}$} & \multicolumn{3}{c}{ injection pain } \\
\cline { 2 - 4 } patient & 0 & 3 & 3 \\
pt. and parent & 0 & 1 & 1 \\
parent & 10 & 8 & 9 \\
\hline \multicolumn{1}{c}{ total } & 10 & 12 & 13 \\
& $(27.8 \%)$ & $(33.3 \%)$ & $(36.1 \%)$ \\
\hline
\end{tabular}

Table 7. Patient's free comments on inferiority of Genotropin KabiQuick to the conventional injector

\begin{tabular}{lrl}
\hline \multicolumn{3}{c}{ Nomplaints of patients or parents } \\
\hline hard to push the plunger & 19 & $(52.8 \%)$ \\
occupies more room for keeping & 5 & $(13.9 \%)$ \\
hard to remove air in GH slution & 5 & $(13.9 \%)$ \\
hard to watch the plunger & 2 & $(5.6 \%)$ \\
\hline
\end{tabular}

the conventional injection respectively (Table $6)$.

Inconveniences of GKQ were arbitrarily pointed out by patients or parents as shown in Table 7. Nineteen patients or parents (52.8\%) commented that the plunger of GKQ was hard to push and hence a longer time was needed to inject the solution. Five (13.9\%) complained that GKQ occupied more room for storage in the refrigerator, and the other 5 that it was not easy to remove the air or bubble in the reconstituted $\mathrm{GH}$ solution in the syringe. Other comments such as difficulty in watching the plunger ( 2 parents), heavy weight ( 1 parent) and difficulty watching the needle (1 patient) were pointed out as inferiorities of the GKQ compared with the conventional syringe.

Patients or parents were asked to state their own choice of injection system, GKQ or the conventional injection, for future treatment, and their answers are listed in Table 8. Twenty-two (61.1\%) preferred GKQ and $5(13.9 \%)$ the conventional system, but $9(25 \%)$ gave non-committal answers. The reasons why the patients or parents preferred the conventional injection system to GKQ are listed in Table 9.

The usefulness of GKQ for each patient
Table 8. Patien's preference for future use

\begin{tabular}{lccc}
\hline & \multicolumn{3}{c}{ preference } \\
\cline { 2 - 4 } $\begin{array}{l}\text { person responsible } \\
\text { for injection }\end{array}$ & KabiQuick & $\begin{array}{c}\text { non-committal } \\
\text { answer }\end{array}$ & $\begin{array}{c}\text { conventional } \\
\text { syringe }\end{array}$ \\
\hline patient & 3 & 3 & 0 \\
pt. and parent & 2 & 0 & 0 \\
parent & 17 & 6 & 5 \\
\hline \multicolumn{1}{c}{ total } & 22 & 9 & 5 \\
& $(61.1 \%)$ & $(25.0 \%)$ & $(13.9 \%)$ \\
\hline
\end{tabular}

Table 9. Reasons why Genotropin KabiQuick was not prefered for future use

\begin{tabular}{lc}
\hline \multicolumn{1}{c}{ reasons } & children \\
\hline hard to push plunger + more pain & 3 \\
hard to push plunger & 1 \\
more pain + more room for storage & 1 \\
\hline
\end{tabular}

Table 10. Doctor's assessment on usefulness of Genotropin KabiQuick for each patient

\begin{tabular}{lrl}
\hline assessment & No. of patients \\
\hline useful & 21 & $(58.3 \%)$ \\
a bit useful & 6 & $(16.7 \%)$ \\
equal to the conventional syringe & 7 & $(19.4 \%)$ \\
not useful & 2 & $(5.6 \%)$ \\
\hline
\end{tabular}

was assessed by the physician in charge as shown in Table 10. GKQ was assessed as useful in 21 patients (58.3\%), somewhat useful in $6(16.7 \%)$, and not useful in $2(5.6 \%)$. The last 2 patients refused to use GKQ for future injections because of pain.

\section{Discussion}

It has been reported that pocket injection pens such as KabiPen [5-7] or Nordiject [8,9] are more convenient than the conventional syringe injection system for patients or parents. But the injection-pen system has some inconvenient problems as follows: the procedure for dissolving $\mathrm{GH}$ and setting a vial into the pen needs several steps, dose adjustment is necessary for each injection, GH solution which is intended for multi-dosing injection contains preservative and the weight of the pen is too heavy. Genotropin KabiQuick 
(GKQ) was devised to eliminate the timeconsuming procedure of reconstitution, vial setting and dose setting, and most of the patients in this study expressed the opinion that GKQ was more convenient in the preparative procedure than the conventional injection system and the dosing adjustment procedure was unnecessary. The time consumed for each injection by GKQ was about half of that for the conventional system. Most of the patients or parents reported that they were able to handle GKQ in a more sanitary condition than the conventional syringe-vial system. About two-thirds of the patients said that handling GKQ was easier than that of the conventional syringe and vial system, but more than half of the patients complained that the plunger of GKQ was hard to push. About one third of the patients complained that GKQ gave a stronger injection pain than the conventional syringe injection, but another one third reported that the pain was less. Injection pain with GKQ was caused presumably by the difficulty in pushing the plunger.

About two-thirds of the patients or parents preferred GKQ to the conventional injection system, but 5 families disliked the new device because of the hard moving plunger and stronger pain.

Using one or two kinds of dose-system of $\mathrm{GKQ}$, all of the patients who ranged in weight between 15 and $55 \mathrm{~kg}$ were able to be treated with $\mathrm{GH}$ of about $0.5 \mathrm{IU} / \mathrm{kg} /$ week. The 9 . 6 -year-old boy with the lowest body weight $(15.3 \mathrm{~kg})$ was injected with 2 IU GKQ 4 times per week $(8 \mathrm{IU} /$ week $=0.52 \mathrm{IU} / \mathrm{kg} /$ week $)$, and the 16.9-year-old boy with the heaviest weight $(55.0 \mathrm{~kg})$ was injected with $4 \mathrm{IU}$ GKQ 7 times per week $(28 \mathrm{IU} /$ week $=0.51 \mathrm{IU} / \mathrm{kg} /$ week $)$. However, a lower dose-system, such as $1 \mathrm{IU}$ $\mathrm{GKQ}$, is thought to be necessary for younger patients with a body weight of less than $15 \mathrm{~kg}$.

These data obtained from the patients in this study are consistent with another report [10]. The doctors who were concerned with this study assessed that GKQ was a useful injection system for most of the patients, and it is concluded that GKQ is a new easy handling device which may provide quick, safe and sterile daily home-injections for nonprofessional persons and may allow more children to take responsibility for their own therapy. But there remains some room for further improvements such as an easily movable plunger, a smaller size device and a lower dose-system.

\section{Acknowledgement}

We express great thanks to Sumitomo Pharmaceutical Co., Ltd. (Osaka, Japan) for supplying Genotropin KabiQuick.

\section{References}

1. Albertsson-Wikland $\mathrm{K}$, Westphal $\mathrm{O}$ and Westgren UU. Daily subcutaneous administration of human growth hormone in growth hormone deficient children. Acta Paediatr Scand 1986; 75: 89-97.

2. Christiansen JS, Orskov $\mathrm{H}$, Binder $\mathrm{C}$ and Kastrup KW. Imitation of normal plasma growth hormone profile by subcutaneous administration of human growth hormone to growth hormone deficient children. Acta Endocrinol(Copenh) 1983; 103: 6-10.

3. Takano K, Shizume K, Hibi I and members of committee for the treatment of pituitary dwarfism in Japan. A comparison of subcutaneous and intramuscular administration of human growth hormone (hGH) and increased growth rate by daily injection of hGH in $\mathrm{GH}$ deficient children. Endocrinol Japon 1988; 35: 477-84.

4. Kastrup KW, Christiansen JS, Andersen $\mathrm{JK}$ and Orskov $\mathrm{H}$. Increased growth rate following transfer to daily S.C. administration from three weeekly i.m. injections of $\mathrm{hGH}$ in growth hormone deficient children. Acta Endocrinol (Copenh) 1983; 104: 15564.

5. Albertsson-Wikland K. Simplified growth hormone therapy - first experience with 
KabiPen. Acta Paediatr Scand(Suppl) 1988; 343: 103-6.

6. Jorgensen. JT, Henrik B and Jorgensen OL. Patient acceptance of Nordiject: A new drug delivery system for growth hormone. DICP, Ann Pharmacother 1991; 25: 585-8.

7. Danielson K, Neumeyer L and Ritzen M. Administration of growth hormone by disposable preloaded syringes. Acta Paediatr Scand (Suppl) 1990; 366: 143-6.

8. Jorgensen JOL, Möller J, Jensen FS, Jorgensen JT and Christiansen JS. Growth hormone administration by means of an injection pen. Pharmacol Toxicol 1989; 65: 96-9.

9. Gluckman PD and Cutfield WS. Evaluation of a pen injector system for growth hormone treatment. Arch Dis Childh 1991; 66: 686-8.

10. Blok GJ, van der Veen EA, Susgaard S and Larsen $F$. Influence of concentration and injection volume on the bioavailability of subcutaneous growth hormone: Comparison of administration by ordinary syringe and by injection pen. Pharmacol Toxicol 1991; 68: 355-9. 